Yoshitoyo Miyauchi MD, Takefumi Sakabe MD, Tsuyoshi Maekawa MD, Toshizoh Ishikawa BS, Hiroshi Takeshita MD

\title{
Responses of EEG, cerebral oxygen consumption and blood flow to peripheral nerve stimulation during thiopentone anaes- thesia in the dog
}

\begin{abstract}
The effects of sciatic nerve stimulation on the electroencephalogram (EEG), cerebral metabolic rate for oxy. gen $\left(\mathrm{CMRO}_{2}\right)$ and cerebral blood flow ( $\mathrm{CBF}$ ) were investigated during thiopentone anaesthesia in dogs. Anaesthetic levels at 15,35,65, 95 and 125 minutes after the start of thiopentone infusion $\left(23 \mathrm{mg} \cdot \mathrm{kg}^{-1} \cdot \mathrm{hr}^{-1}\right)$ were designated levels $I, I I, I I I, I V$ and $V$, respectively. The effects of stimulation for $5 \mathrm{~min}$ were tested at each level. At level I (plasma thiopentone concentration; $15 \pm$ $2 \mu \mathrm{g} \cdot \mathrm{ml}^{-1}$ ), the EEG was activated with stimulation and $\mathrm{CMRO}_{2}$ and $\mathrm{CBF}$ increased by a maximum of 16 and 15 per cent, respectively. The increase in $\mathrm{CMRO}_{2}$ and $\mathrm{CBF}$ was significant for five and four minutes, respectively, though the increase became less with time. At level II $\left(27 \pm 3 \mu \mathrm{g} \cdot \mathrm{ml}^{-1}\right)$, the $\mathrm{CMRO}_{2}$ and $\mathrm{CBF}$ increased at one minute by eight and nine per cent, the increase being accompanied by transient EEG activation. At the three
\end{abstract}

Key words

ANAESTHETICS, INTRAVENOUS: thiopentone. BRAIN: electroencephalogram; stimulation. BRAIN: blood flow, metabolism.

From the Department of Anesthesiology, Yamaguchi University School of Medicine, Ube, Yamaguchi, Japan. Address correspondence to: Yoshitoyo Miyauchi, Department of Anesthesiology, Yamaguchi University School of Medicine, 1144 Kogushi, Nishi-ku, Ube, Yamaguchi, 755, Japan. deepest levels $I I I, I V$ and $V(37 \pm 6,42 \pm 6,49 \pm$ $6 \mu \mathrm{g} \cdot \mathrm{ml}^{-1}$ ), the EEG, $\mathrm{CMRO}_{2}$ and $\mathrm{CBF}$ remained unchanged with stimulation. The results suggest the existence of the tight coupling between the EEG, $\mathrm{CMRO}_{2}$ and $C B F$ and of a threshold level of thiopentone to block the response to peripheral stimulation during thiopentone anaesthesia.

A dose of barbiturate sufficient to produce an anaesthetic state is known to cause electroencephalographic (EEG) slowing which is accompanied by the reduction of the cerebral metabolic rate for oxygen $\left(\mathrm{CMRO}_{2}\right)$ and cerebral blood flow (CBF). ' This suggests that a close relationship exists between function, metabolism and blood flow during barbiturate anaesthesia, as observed during wakefulness ${ }^{2}$ and in chronic brain disease. ${ }^{3}$ However, such a relationship does not necessarily exist under all anaesthetic circumstances, since it is known that volatile anaesthetics cause EEG slowing and a decrease in $\mathrm{CMRO}_{2}$, but an increase in CBF. These studies on $\mathrm{CMRO}_{2}$ and $\mathrm{CBF}$ have been concerned only with the effects of anaesthetics without stimulation. In our laboratory, Kuramoto et al. ${ }^{4}$ studied modification of EEG, $\mathrm{CMRO}_{2}$ and $\mathrm{CBF}$ responses to stimulation by halothane, methoxyflurane, nitrous oxide and morphine. The data suggested that the coupling of the EEG and $\mathrm{CMRO}_{2}$ was maintained but the coupling of $\mathrm{CMRO}_{2}$ and $\mathrm{CBF}$ varied with anaesthetics and anaesthetic levels. In the 


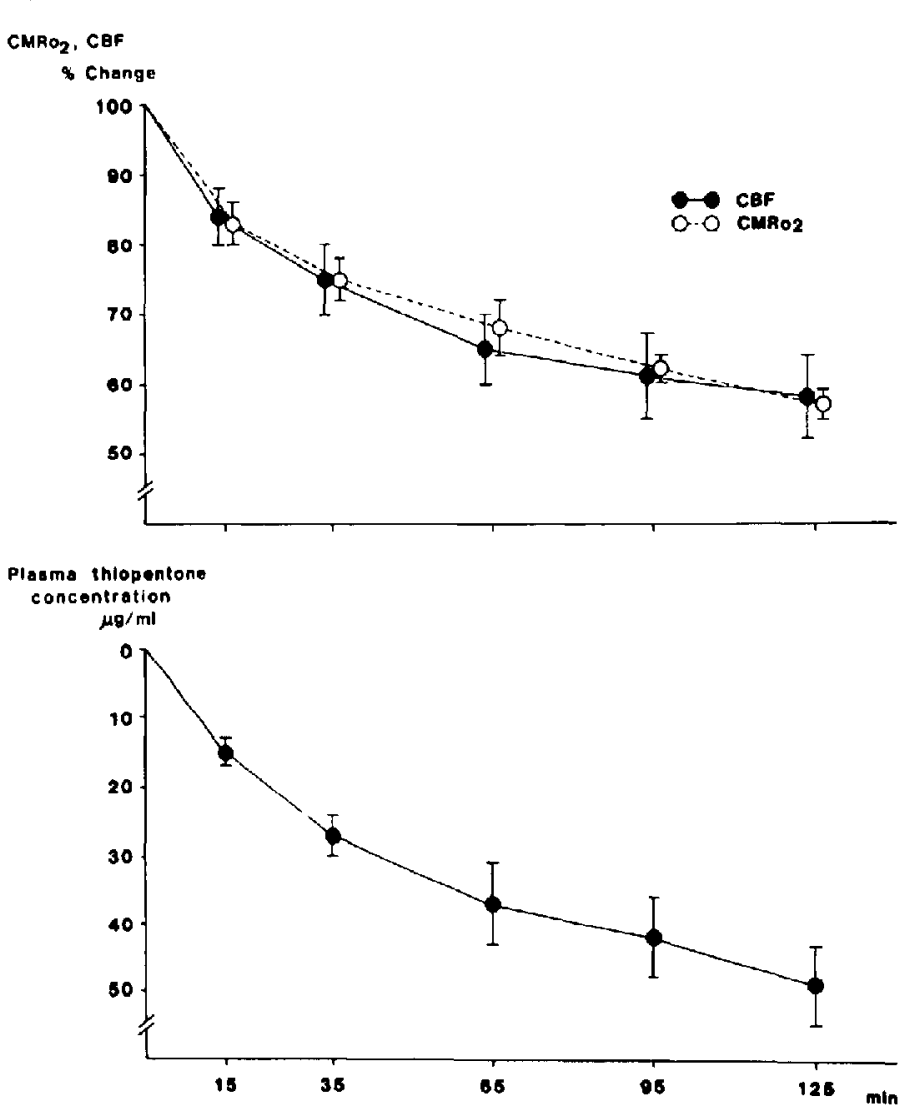

FIGURE 1 Changes of mean $\mathrm{CMRO}_{2}, \mathrm{CBF}$ and absolute plasma concentrations of thiopentone. Vertical bars indicate \pm SEM. The times, 15, 35, 65, 95 and $125 \mathrm{~min}$ after the start of infusion correspond to anaesthetic levels I, II, III, IV and V, respectively.

present study, this approach was extended to thiopentone which is known to be a potent cerebral vasoconstrictor. We found tight coupling between $\mathrm{EEG}, \mathrm{CMRO}_{2}$ and $\mathrm{CBF}$ during stimulation.

\section{Methods}

Ten unpremedicated mongrel dogs weighing 10 to $21 \mathrm{~kg}$ were anaesthetized with 1 to 1.5 per cent halothane, in 40 per cent oxygen and nitrogen. Succinylcholine, $2 \mathrm{mg} \cdot \mathrm{kg}^{-1}$, was given intramuscularly to facilitate tracheal intubation and thereafter, was given at the rate of $1 \mathrm{mg} \cdot \mathrm{kg}^{-1} \cdot \mathrm{hr}^{-1}$. Ventilation was controlled by a Harvard animal respirator to maintain $\mathrm{PaO}_{2}$ at $25 \pm 0.3 \mathrm{kPa}$ (mean \pm SEM) and $\mathrm{PaCO}_{2}$ at $5.1 \pm 0.1 \mathrm{kPa}$. Oesophageal temperature and haemoglobin levels were maintained at $37 \pm 0.1^{\circ} \mathrm{C}$ and $12 \pm 0.2 \mathrm{~g} \cdot \mathrm{dL}^{-1}$, respectively.

Both femoral arteries were cannulated for blood sampling and pressure measurement, and both femoral veins were cannulated for the infusion of blood, lactated Ringer's solution and drugs. Both sciatic nerves were carefully exposed and cut at the thigh level. Their proximal ends were then gently placed on bipolar silver-silver chloride electrodes, separated by $1 \mathrm{~cm}$. Sciatic nerve temperature was maintained by circulating warmed liquid paraffin around the exposed area. The surgical preparation used for the measurement of hemispheric CBF was as originally described by Michenfelder et $a l^{5}$ and 
subsequently modified by Oshita et al. ${ }^{6}$ After the animal was heparinized, using an initial dose of $3 \mathrm{mg} \cdot \mathrm{kg}^{-1}$, then $0.5 \mathrm{mg} \cdot \mathrm{kg}^{-1} \cdot \mathrm{hr}^{-1}$, the sagittal sinus was cannulated. The drained blood was returned to the left external jugular vein through the draining cannula.

An electromagnetic flowmeter probe (lumen diameter $3 \mathrm{~mm}$ ) was incorporated $1 \mathrm{~cm}$ away from the draining portion of the sinus. To ensure exact measurements, the flowmeter (Nihon Koden MF46) incorporated a nonocclusive zero and a 3-sec time constant. In addition, the flowmeter was frequently calibrated by direct timed measurements of the sagittal sinus blood flow. After postmortem injection of vinyl acetate into the sinus and subsequent dissection, the weight of the brain drained by the cannula was found to average $41 \pm 1$ per cent of the total brain, and the absence of extracerebral venous connections to the sagittal sinus was confirmed. This percentage is used to correct units of flow from $\mathrm{mL} \cdot \mathrm{min}^{-1}$ to $\mathrm{mL} \cdot 100 \mathrm{~g}^{-1} \cdot \mathrm{min}^{-1}$. The oxygen content of the arterial and sagittal sinus blood was calculated from measurements of oxyhemoglobin (IL 282 CO-oxymeter) and oxygen tension ( $\mathrm{ABL}-2$ electrode). Blood $\mathrm{pH}$ and $\mathrm{PCO}_{2}$ values were measured with appropriate electrodes. The $\mathrm{CMRO}_{2}$ was calculated as the product of $\mathrm{CBF}$ and the difference in oxygen content of the arterial and sagittal sinus blood. Cerebral vascular resistance (CVR) was calculated as the ratio of mean arterial pressure (MAP) to CBF. The EEG was continuously recorded using parietal bipolar silversilver chloride electrodes.

After completion of the surgical preparation, the inspired halothane concentration was decreased to 0.2 per cent in 40 per cent oxygen and nitrogen, and these concentrations of background gases were maintained throughout the study. At least one hour was allowed to elapse before the start of the measurements. Lidocaine, $5 \mathrm{mg} \cdot \mathrm{kg}^{-1}(0.5$ per cent solution), was injected into the skin and muscle of the head and at the areas where the cannulae were placed. Additional lidocaine (half of the initial dose) was given hourly.

The mean values of $\mathrm{CMRO}_{2}$ and $\mathrm{CBF}$ were obtained from five to seven consecutive determinations before the start of thiopentone infusion. Thereafter, thiopentone was infused intravenously at a constant rate of $23 \mathrm{mg} \cdot \mathrm{kg}^{-1} \cdot \mathrm{hr}^{-1}$ and the anaesthetic levels at $15,35,65,95$ and 125 minutes were designated level I, II, III, IV and V. At each level of anaesthesia, a control measurement was obtained one minute before stimulation. Following the control measurement, bilateral sciatic nerve stimulation was done by application of supramaximum rectangular stimuli (6 volts, $0.1 \mathrm{msec}, 100$ $\mathrm{Hz}$ ) for $5 \mathrm{~min}$. During the stimulation, $\mathrm{CMRO}_{2}$ and CBF were measured at 1 -min intervals, along with the continuous monitoring of EEG. A decrease in amplitude or an increase in frequency, or both were considered a manifestation of EEG activation. Plasma thiopentone concentrations were measured at each level by gas chromatography (Shimazu GC-4).

Statistical differences were tested by one-way analysis of variance for repeated measurement with the least significant difference test for multiple comparisons. $\mathbf{P}<0.05$ was considered significant.

\section{Results}

Before thiopentone infusion, the EEG mainly consisted of $13-20 \mathrm{~Hz}$ waves and the mean $\mathrm{CMRO}_{2}$ and $\mathrm{CBF}$ were $6.0 \pm 0.2$ and $59 \pm 3 \mathrm{~mL}$. $100 \mathrm{~g}^{-1} \cdot \mathrm{min}^{-1}$, respectively. Per cent changes of $\mathrm{CMRO}_{2}$ and $\mathrm{CBF}$ during thiopentone infusion as compared to the values before thiopentone are illustrated in Figure 1 in association with plasma concentrations of thiopentone. Plasma thiopentone concentration was $15 \pm 2,27 \pm 3,37 \pm 6,42 \pm 6$ and $49 \pm 6 \mu \mathrm{g} \cdot \mathrm{ml}^{-1}$ (mean \pm SEM) at levels I, II, III, IV and V, respectively. The values represent the mean of the two samples obtained before and at the end of the 5-minute stimulation period. At level I, the $\mathrm{CMRO}_{2}$ and CBF decreased to 83 and 84 per cent of the value before thiopentone, respectively. These changes were accompanied by EEG slowing, which consisted of 2 to $8 \mathrm{~Hz}$ superimposed on 8 to $13 \mathrm{~Hz}$ waves. Thereafter, the mean $\mathrm{CMRO}_{2}$ and CBF decreased progressively in association with further slowing of the EEG (levels II and III) and with a decrease in amplitude (level IV). At level V, while the EEG showed burst suppression, the mean $\mathrm{CMRO}_{2}$ and $\mathrm{CBF}$ decreased to 57 and 58 per cent of the value before thiopentone, respectively.

The effects of sciatic nerve stimulation on cerebral metabolism and circulation are summarized in the Table. Representative EEG patterns are shown in Figure 2. With the stimulation at level I, the EEG was highly activated and the mean $\mathrm{CMRO}_{2}$ and CBF increased by a maximum of 16 and 15 per cent at one minute, and remained elevated for five- and 


Level I Povel III Forol

FIGURE 2 Representative EEGs before (control) and, at $\mathrm{l}$ and $5 \mathrm{~min}$ after the start of stimulation at each anaesthetic level. EEG activation was observed at level I $(1,5 \mathrm{~min})$ and II ( $1 \mathrm{~min}$ ) but not at the three deepest levels.

four-minute stimulation periods, respectively, with a tendency for a decrease in response with time. At level II, the EEG initially showed an activated pattern, and the $\mathrm{CMRO}_{2}$ and $\mathrm{CBF}$ increased significantly by eight and nine per cent, respectively, at the first minute. Thereafter, the changes substantially decreased with time. At levels III, IV and $\mathrm{V}$, the EEG, $\mathrm{CMRO}_{2}$ and CBF were unaffected by the stimulation. Regression analysis between the $\mathrm{CMRO}_{2}$ and $\mathrm{CBF}$ at the five different anaesthetic levels revealed a significant correlation ( $r=0.98$ ) between metabolism and flow as shown in Figure 3.

\section{Discussion}

The present study has demonstrated the existence of a coupling between the EEG, $\mathrm{CMRO}_{2}$ and $\mathrm{CBF}$ responses to sciatic nerve stimulation during thiopentone anaesthesia at all anaesthetic levels tested. The tight coupling between metabolism and flow was distinct when pooled $\mathrm{CMRO}_{2}$ and $\mathrm{CBF}$ values at the different levels were tested for regression analysis. The magnitude of the increase in $\mathrm{CMRO}_{2}$ and $\mathrm{CBF}$ with stimulation at level I and II could be biased by baseline shifts of $\mathrm{CMRO}_{2}$ and $\mathrm{CBF}$, particularly during the latter half of the stimulation period, since $\mathrm{CMRO}_{2}$ and $\mathrm{CBF}$ were decreased by the continuous thiopentone infusion. However, this underestimation would be at most 0.5 per cent for each one minute period for $\mathrm{CMRO}_{2}$ and $\mathrm{CBF}$ change at level I and II, and does not affect the conclusions. The decrease in response of $\mathrm{CMRO}_{2}$ and $\mathrm{CBF}$ to stimulation with time, being marked in level II, may indicate the deepening level of anaesthesia with thiopentone and/or the accommodation of the sciatic nerve itself or the somatosensory pathway to the stimulation, as also observed by Kuramoto et al. ${ }^{4}$ The authors had anticipated EEG activation and increases in $\mathrm{CMRO}_{2}$ and $\mathrm{CBF}$ even 
TABLE Effects of scitiatic nerve stimulation on cerebral metabolism and circulation

\begin{tabular}{|c|c|c|c|c|c|}
\hline Level & $\begin{array}{l}\text { Time after } \\
\text { stimulation } \\
(\mathrm{min})\end{array}$ & $\begin{array}{l}\mathrm{CMRO}_{2} \\
\left(\mathrm{ml} \cdot 100 \mathrm{~g}^{-1} \cdot \mathrm{min}^{-1}\right)\end{array}$ & $\begin{array}{l}C B F \\
\left(m l \cdot 100 g^{-1} \cdot \mathrm{min}^{-1}\right)\end{array}$ & $\begin{array}{l}M A P \\
(m m H g)\end{array}$ & $\begin{array}{l}\mathrm{CVR} \\
\left(\mathrm{mmHg} \cdot \mathrm{ml} \cdot 100 \mathrm{~g}^{-1} \cdot \mathrm{min}^{-1}\right)\end{array}$ \\
\hline \multirow[t]{6}{*}{ I } & Control & $4.95 \pm 0.16$ & $49.1 \pm 2.5$ & $94 \pm 4$ & $1.96 \pm 0.14$ \\
\hline & 1 & $5.76 \pm 0.23^{*}$ & $56.3 \pm 3.0^{*}$ & $96 \pm 7$ & $1.74 \pm 0.15^{*}$ \\
\hline & 2 & $5.46 \pm 0.17^{*}$ & $55.1 \pm 2.9^{*}$ & $94 \pm 5$ & $1.77 \pm 0.14^{*}$ \\
\hline & 3 & $5.57 \pm 0.20^{*}$ & $54.2 \pm 3.0^{*}$ & $92 \pm 4$ & $1.76 \pm 0.14^{*}$ \\
\hline & 4 & $5.42 \pm 0.19^{*}$ & $52.6 \pm 2.9^{*}$ & $91 \pm 4$ & $1.79 \pm 0.15^{*}$ \\
\hline & 5 & $5.50 \pm 0.21^{*}$ & $51.9 \pm 3.1$ & $91 \pm 4$ & $1.82 \pm 0.15^{*}$ \\
\hline \multirow[t]{6}{*}{ II } & Control & $4.52 \pm 0.18$ & $43.8 \pm 2.9$ & $92 \pm 4$ & $2.17 \pm 0.14$ \\
\hline & 1 & $4.86 \pm 0.24^{*}$ & $47.6 \pm 3.3^{*}$ & $85 \pm 5^{*}$ & $1.87 \pm 0.16^{*}$ \\
\hline & 2 & $4.84 \pm 0.24$ & $46.3 \pm 3.3$ & $87 \pm 4^{*}$ & $1.96 \pm 0.15^{*}$ \\
\hline & 3 & $4.72 \pm 0.23$ & $45.4 \pm 3.3$ & $86 \pm 4^{*}$ & $1.98 \pm 0.16^{*}$ \\
\hline & 4 & $4.71 \pm 0.24$ & $44.4 \pm 3.2$ & $85 \pm 4^{*}$ & $2.00 \pm 0.16^{*}$ \\
\hline & 5 & $4.73 \pm 0.24$ & $44.1 \pm 3.3$ & $85 \pm 4^{*}$ & $2.01 \pm 0.16^{*}$ \\
\hline \multirow[t]{6}{*}{ III } & Control & $4.09 \pm 0.21$ & $38.0 \pm 2.9$ & $87 \pm 4$ & $2.41 \pm 0.21$ \\
\hline & 1 & $4.13 \pm 0.20$ & $38.5 \pm 2.9$ & $74 \pm 5^{*}$ & $2.04 \pm 0.22^{*}$ \\
\hline & 2 & $4.13 \pm 0.21$ & $38.0 \pm 3.0$ & $79 \pm 5^{*}$ & $2.19 \pm 0.23^{*}$ \\
\hline & 3 & $4.17 \pm 0.21$ & $37.8 \pm 3.0$ & $78 \pm 5^{*}$ & $2.18 \pm 0.23^{*}$ \\
\hline & 4 & $4.13 \pm 0.20$ & $37.5 \pm 3.0$ & $77 \pm 6^{*}$ & $2.17 \pm 0.22^{*}$ \\
\hline & 5 & $4.12 \pm 0.17$ & $37.4 \pm 2.9$ & $77 \pm 5^{*}$ & $2.18 \pm 0.23^{*}$ \\
\hline \multirow[t]{6}{*}{ IV } & Control & $3.72 \pm 0.14$ & $35.9 \pm 3.2$ & $88 \pm 4$ & $2.61 \pm 0.24$ \\
\hline & 1 & $3.76 \pm 0.15$ & $36.3 \pm 3.4$ & $73 \pm 4^{*}$ & $2.21 \pm 0.24^{*}$ \\
\hline & 2 & $3.72 \pm 0.16$ & $35.7 \pm 3.4$ & $77 \pm 4^{*}$ & $2.33 \pm 0.23 *$ \\
\hline & 3 & $3.72 \pm 0.15$ & $35.7 \pm 3.3$ & $78 \pm 4^{*}$ & $2.33 \pm 0.23^{*}$ \\
\hline & 4 & $3.73 \pm 0.14$ & $35.7 \pm 3.3$ & $77 \pm 4^{*}$ & $2.32 \pm 0.23^{*}$ \\
\hline & 5 & $3.74 \pm 0.14$ & $35.2 \pm 3.3$ & $76 \pm 4^{*}$ & $2.32 \pm 0.22^{*}$ \\
\hline \multirow[t]{6}{*}{ V } & Control & $3.43 \pm 0.12$ & $34.2 \pm 3.1$ & $84 \pm 4$ & $2.63 \pm 0.25$ \\
\hline & 1 & $3.48 \pm 0.13$ & $33.5 \pm 3.0$ & $76 \pm 4^{*}$ & $2.41 \pm 0.23^{*}$ \\
\hline & 2 & $3.49 \pm 0.12$ & $33.7 \pm 3.1$ & $77 \pm 4^{*}$ & $2.44 \pm 0.25^{*}$ \\
\hline & 3 & $3.52 \pm 0.12$ & $33.8 \pm 3.1$ & $76 \pm 4^{*}$ & $2.42 \pm 0.25^{*}$ \\
\hline & 4 & $3.50 \pm 0.12$ & $33.8 \pm 3.0$ & $77 \pm 5^{*}$ & $2.45 \pm 0.26^{*}$ \\
\hline & 5 & $3.50 \pm 0.12$ & $33.8 \pm 3.1$ & $78 \pm 5^{*}$ & $2.46 \pm 0.25^{*}$ \\
\hline
\end{tabular}

Values are Mean \pm SEM

*Significantly different from control $(\mathrm{p}<0.05)$.

during the deeper levels of thiopentone anaesthesia (levels III, IV and V), since barbiturates are known to be weak in blocking noxious stimuli. However, cerebral metabolic and circulatory responses to the sciatic nerve stimulation became undetectable with increasing dose of thiopentone. Therefore, the threshold of the plasma concentration of thiopentone at which EEG, metabolic and circulatory responses to stimuli would be blocked seems to be somewhere between $27 \mu \mathrm{g} \cdot \mathrm{ml}^{-1}$ (level II) and $37 \mu \mathrm{g} \cdot \mathrm{ml}^{-1}$ (level III). This plasma level of thiopentone is slightly lower than the reported values in humans for loss of comeal reflex and trapezius muscle response $\left(39-42 \mu \mathrm{g} \cdot \mathrm{ml}^{-1}\right)$ which are reported to be well correlated with the response to surgical stimulation. ${ }^{7}$

Meyer et $a l^{8}$ reported that stimulation of the brain-stem reticular formation produced EEG activation and increases in $\mathrm{CMRO}_{2}$ and $\mathrm{CBF}$ of eight and ten per cent, respectively, during pentobarbitone and ether anaesthesia in the monkey, but with femoral nerve stimulation, there was no significant change in $\mathrm{CMRO}_{2}$ and CBF. The latter was only tested in two monkeys. The inexact nature of their reported anaesthetic conditions make detailed comparison difficult. Langfitt and Kassell ${ }^{9}$ reported that 


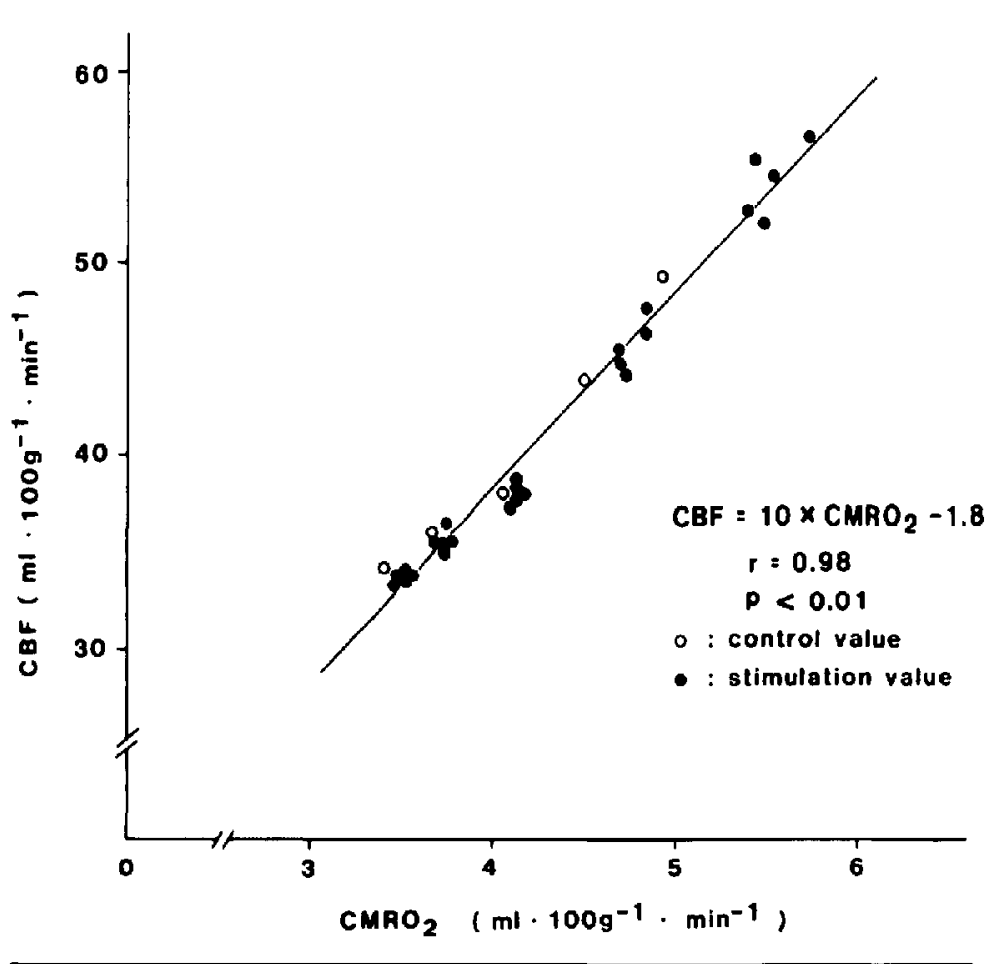

FIGURE 3 Linear regression analysis between the $\mathrm{CMRO}_{2}$ and $\mathrm{CBF}$ at the five different anaesthetic levels.

the stimulation of the lower brain-stem invariably altered the EEG pattern and produced an increase in CBF without a change in blood pressure in five cord-sectioned monkeys anaesthetized with pentobarbitone. They concluded that the most likely explanation for the cerebral vasodilatation was a neurogenic mechanism, because of the very short time between stimulation and response. However, they did not measure $\mathrm{CMRO}_{2}$, making examination of the relationship between metabolism and blood flow impossible.

In rabbits anaesthetized with chloralose and urethane, Gregory et al. ${ }^{10}$ reported that increased CBF due to sciatic nerve stimulation paralleled an increase in local metabolism, and that the increase in $\mathrm{CBF}$ was independent of the change in MAP, since sciatic nerve stimulation resulted in a decrease in MAP. Increase of glucose consumption in the discrete area in the spinal cord and cerebral cortex with peripheral nerve stimulation during pentobar- bitone or nitrous oxide anaesthesia has been also reported. ${ }^{11}$ In this study, however, the effects of different doses of pentobarbitone was not tested. The present study shows the existence of threshold level of thiopentone to block the response to stimulation. The parallel change in $\mathrm{CMRO}_{2}$ and CBF with stimulation observed in the present study suggests that cerebral vasodilatation occurs in response to demand for oxygen during increased neuronal activities.

Kuramoto et al. ${ }^{4}$ studied modification of the relationship between cerebral metabolism, blood flow and EEG by sciatic nerve stimulation during different types of anaesthesia. During halothane anaesthesia, sciatic nerve stimulation produced a striking increase in CBF even at the stage where no EEG and $\mathrm{CMRO}_{2}$ response were seen. In contrast with morphine, which is a mild cerebral vasoconstrictor, there was coupling between $\mathrm{CMRO}_{2}$ and $\mathrm{CBF}$ during stimulation. They suggested that 
coupling between $\mathrm{CMRO}_{2}$ and $\mathrm{CBF}$ may be related to the cerebral vascular effects of individual anaesthetics, and appears to be dependent on whether a specific drug dilates or constricts cerebral vessels. This was supported by the present results, since thiopentone is known to be a potent cerebral vasoconstrictor.

In the present study, MAP decreased with stimulation at levels II, III, IV and V. Such a decrease in MAP was also observed with sciatic nerve stimulation during deep halothane or methoxyflurane anaesthesia. ${ }^{4}$ However, during light halothane, methoxyflurane and morphine anaesthesia, MAP increased with peripheral stimulation. ${ }^{4}$ This suggests that individual effects of anaesthetics on vasomotor response to peripheral stimulation may be variable.

It is well known that in neurosurgical anaesthesia an increase in CBF may be harmful, especially for the patient who already had an increased intracranial pressure. ${ }^{12}$ In this respect, thiopentone, if the adequate dose is given, does prevent a striking increase in CBF with peripheral stimulation as seen in halothane, and, hence, seems to be a suitable agent for the patient with increased intracranial pressure.

In summary, during thiopentone anaesthesia there was a tight coupling between the EEG, $\mathrm{CMRO}_{2}$ and $\mathrm{CBF}$, either with or without sciatic nerve stimulation. At the EEG stage of marked slow waves or burst suppression, there were no cerebral metabolic and circulatory responses to supramaximum stimulation of the sciatic nerve in the dog.

\section{References}

1 Pierce EC Jr, Lambertsen CJ, Deutsch S et al. Cerebral circulation and metabolism during thiopental anaesthesia and hyperventilation in man. $\mathbf{J}$ Clin Invest 1962; 41: 1664-71.

2 Olesen $J$. Contralateral focal increase of cerebral blood flow in man during arm work. Brain 1971; 94: 635-46.

3 Ingvar DH, Sjölund B, Ardö A. Correlation between dominant EEG frequency, cerebral oxygen uptake and blood flow. Electroenceph Clin Neurophysiol 1976; 41: 268-76.

4 Kuramotot $T$, Oshita $S$, Takeshita H, IshikawaT. Modification of the relationship between cerebral metabolism, blood flow, and electroencephalogram by stimulation during anesthesia in the dog. Anesthesiology 1979; 51: 211-7.

5 Michenfelder JD, MessickJM Jr, Theye RA. Simultaneous cerebral blood flow measured by direct and indirect methods. J Surg Res 1968; 8: 475-81.

6 Oshita S, Ishikawa T, Tokutsu Y, Takeshita H. Cerebral circulatory and metabolic stimulation with nitrous oxide in the dog. Reconfirmation by the simultaneous measurement of cerebral blood flow using direct and Kety-Schmidt methods. Acta Anaesthesiol Scand 1979; 23: 177-81.

7 Becker KE Jr. Plasma levels of thiopental necessary for anesthesia. Anesthesiology 1978; 49: 192-6.

8 Meyer JS, Nomura F, Sakamoto K, Kondo A. Effect of stimulation of the brain-stem reticular formation on cerebral blood flow and oxygen consumption. Electroenceph Clin Neurophysiol 1969; 26: 125-32.

9 Langfitt $T W$, Kassel $N F$. Cerebral vasodilatation produced by brain-stem stimulation; neurogenic control vs. autoregulation. Am J Physiol 1968; 215: 90-7.

10 Gregory PC, Anderson PCGM, Haper AM. Coupling of cerebral blood flow and metabolism following somato-sensory stimulation in rabbits. Acta Neurol Scand 1977; 56: suppl. 254-5.

11 Crosby $G$, Crane AM, Jehle J, Sokoloff $L$. The local metabolic effects of somatosensory stimulation in the central nervous system of rats given pentobarbital or nitrous oxide. Anesthesiology 1983; 58: 38-43.

12 Shapiro HM. Intracranial hypertension; therapeutic and anesthetic considerations. Anesthesiology 1975; 43: $445-71$. 
Résumé

Les effets de la stimulation du nerf sciatique sur l'electroencéphalogramme (EEG), consommation d'oxygène par le cerveau $\left(\mathrm{CMRO}_{2}\right)$ ainsi que le fot cérébral (CBF) ont été investigués lors de l'anesthésie au thiopentone chez les chiens, Les niveaux d'anesthésie d 15, 35, 65, 95 et 125 minutes après le début de la perfusion du thiopentone $\left(23 \mathrm{mg} \cdot \mathrm{kg}^{-1} \cdot \mathrm{hr}^{-1}\right)$ ont été définis comme étant les niveaux I, II, III, IV et V. Les effers d'une stimulation de cing minutes ont été étudiés à chaque niveau. Au niveau I (concentration plasmatique de thiopentone; $\left.15 \pm 2 \mu \mathrm{g} \cdot \mathrm{ml}^{-1}\right), l^{\prime} E E G$ a été activé par la stimulation et la $\mathrm{CMRO}_{2}$ et le CBF ont augmenté de 16 et 15 pour cent respectivement. L'augmentation de la $\mathrm{CMRO}_{2}$ et du CBF a été significative pour cinq et quatre minutes respectivement même si l'augmentation a diminué avec le temps. Au niveau II $\left(27 \pm 3 \mu \mathrm{g} \cdot \mathrm{ml}^{-1}\right)$, le $\mathrm{CMRO}_{2}$ et le $\mathrm{CBF}$ ont augmenté d une minute de huit et neuf pour cent, l'augmentation étant accompagnée par une activation transitoire de l'EEG. Aux trois niveaux les plus profonds III, IV et $V(37 \pm 6,42 \pm 6,49 \pm$ $6 \mu \mathrm{g} \cdot \mathrm{ml}^{-1}$ ). l'EEG, la $\mathrm{CMRO}_{2}$ et le $\mathrm{CBF}$ sont restés inchangés avec la stimulation. Les résultats suggèrent une liaison étroite entre l' $E E G$, la $\mathrm{CMRO}_{2}$ et le $\mathrm{CBF}$ ainsi que les niveaux du thiopentone qui bloqueraient la réponse d̀ une stimulation périphérique. 